\title{
Risk factors for fecal carriage of multidrug-resistant Escherichia coli in a college community: a penalized regression model
}

\author{
Yuan $\mathrm{Hu}^{\mathrm{a}^{*}}$, Julia Rubin $^{\mathrm{b}^{*}}$, Kaitlyn Mussio ${ }^{\mathrm{b}}$, Lee W. Riley ${ }^{\mathrm{c} * *}$ \\ 5 a Division of Epidemiology, School of Public Health, University of California Berkeley, \\ Berkeley 94720, USA \\ ${ }^{\mathrm{b}}$ Division of Environmental Health Science, School of Public Health, University of California \\ Berkeley, Berkeley 94720, USA \\ c Division of Infectious Diseases and Immunology, School of Public Health, University of \\ California Berkeley, Berkeley 94720, USA
}

\begin{abstract}
Background: Bacterial antimicrobial resistance is a serious global public health threat. Intestinal commensal drug-resistant bacteria have been suggested as an important reservoir of antimicrobial resistant genes (ARGs), which may be acquired via food. We aimed to identify risk factors associated with fecal carriage of drug-resistant commensal Escherichia coli (E. coli) among healthy adults focused on their dietary habit.
\end{abstract}

Methods: We conducted a cross-sectional study targeting healthy adult volunteers in a college community. Fecal samples and questionnaires were obtained from 113 volunteers. We conducted backward elimination logistic regression and least absolute shrinkage and selection (LASSO) methods to identify risk factors.

Results: We analyzed responses from 81 of 113 volunteers who completed the questionnaire. The logistic regression and LASSO methods identified red meat consumption to be associated with increased risk ( $\mathrm{OR}=6.13[1.83-24.2]$ and 1.82, respectively) and fish consumption with reduced risk $(\mathrm{OR}=0.27[0.08-0.85]$ and 0.82$)$ for the carriage of multidrug-resistant E. coli, adjusted for gender, employment status, frequently-used supermarket, and previous travel.

Conclusions: Dietary habits are associated with the risk of fecal carriage of multidrug-resistant E. coli. This study supports the growing evidence that food may be an important source of ARGs present in human commensal E. coli. regression, LASSO, penalized regression, surveillance, gut microbiota 
medRxiv preprint doi: https://doi.org/10.1101/2020.11.16.20231969; this version posted November 18, 2020. The copyright holder for this preprint (which was not certified by peer review) is the author/funder, who has granted medRxiv a license to display the preprint in perpetuity.

It is made available under a CC-BY-NC-ND 4.0 International license .

\section{Footnote}

1. *These authors contributed equally.

2. Conflict of interests

Authors do not have a commercial or other association that might pose a conflict of interest.

\section{Fundings}

This study was supported by Centers for Disease Control and Prevention's Combating Antibiotic Resistance BAA 200-2016-91939.

4. **Corresponding author: Lee W. Riley

Email: lwriley@berkeley.edu

Phone: (510) 642-9200

5. Julia Rubin: Sonoma county department of health services Kaitlyn Mussio: Independent

6. All authors agreed to be contacted 


\section{Introduction}

Antimicrobial drug resistance is one of the most pressing global public health concerns of our time, threatening the effective prevention and treatment of infectious diseases in every country [1] [2]. In the United States, U.S. Department of Health \& Human Services have declared the necessity to take national action and to strengthen surveillance system to combat the spread of antimicrobial resistance [3]. In particular, several drug-resistant Gram-negative bacterial species belonging to Enterobacteriaceae have come to be designated by Centers for Disease Control and Prevention (CDC) and the World Health Organization (WHO) to be "urgent-threat" or "priority 1" pathogens [4].

Among the Gram-negative bacterial pathogens, Escherichia coli (E. coli) is the most frequent cause of common extraintestinal infections, including urinary tract infections (UTI) and bloodstream infections (BSI) [5]. They are referred to as extraintestinal pathogenic E. coli (ExPEC) [6]. The prevalence and incidence of infections caused by drug-resistant ExPEC have been rapidly increasing worldwide [7,8].

Major sources of drug-resistant Gram-negative bacteria include the environment such as contaminated water [9], food including meat $[10,11]$ and vegetables $[12,13]$, and healthcare settings [14]. Additionally, intestinal commensal drug-resistant bacteria have been reported as an important reservoir of antimicrobial drug resistance genes (ARGs) $[15,16]$. E. coli is a member of the commensal flora of human and other warm-blooded animal intestinal tracts. As such, they can acquire ARGs by horizontal gene transfer [17] from drug-resistant E. coli strains and other Gram-negative bacteria that enter the intestinal tract via exposures to contaminated food, water, and other external sources. E. coli can be transmitted through contaminated water or food, or through contact with people and other animals [18]. Thus, risk factors for fecal carriage of drug-resistant commensal E. coli and ARGs could include exposures to environmental sources of drug-resistant bacteria, in addition to traditional risks such as prior use of antibiotics [19,20] or healthcare-associated infections [21,22].

In our previous study, we found $81 \%$ of healthy volunteers at a college community to harbor intestinal drug-resistant commensal Gram-negative bacteria [23]. They included 12 species of 
Gram-negative bacteria that harbored a variety of ARGs and integrons that are frequently found among extraintestinal pathogenic E. coli (ExPEC) [23]. Risk factors for the carriage of these ARGs, however, were not determined. drug resistant E. coli [24], but found no studies from North America that met the criteria to be included in the review, even though North America is a major food-exporting region in which antibiotics are heavily used in food animal husbandry and agriculture. Also, we could not find studies that particularly focused on dietary behavior as a risk factor for intestinal carriage of drug-resistant E. coli or ARGs. Two studies reported significant association between food and carriage of drug resistant bacteria. One study reported that raw milk consumption increases the risk of intestinal colonization of drug resistant bacteria [25], and another reported food consumption from street vendors as a travel-associated risk factor [26].

Here, we designed and implemented a cross sectional study to identify dietary risk factors associated with fecal carriage of multidrug-resistant commensal E. coli among healthy adult population in a college community. We focused on the carriage of multidrug-resistant E. coli in particular because of its clinical relevance to diseases such as UTI and BSI. Because of the relatively small sample size of the study, we used multiple logistic regression and penalized regression methods to select the best model to identify risks.

\section{Materials and Methods}

\subsection{Sample collection, antimicrobial susceptibility screening, and questionnaires}

As previously described by Rubin et al. [23], we prospectively collected and cultured fecal swab samples from 113 healthy volunteers at a university campus in northern California between June and October 2018. Eligible participants included both men and women between 18 and 65 years of age, with no medical history of urinary tract corrective surgery or abnormality, or bladder catheterizing or hospitalization within the 6 months prior to sample collection. At recruitment, participants were provided a collection kit containing a Blair transport media rectal swab (Becton Dickinson BBL), two bio-safety bags, and detailed collection instructions. Each kit also included a questionnaire regarding antibiotic use, history of UTI, as well as diet and lifestyle 
It is made available under a CC-BY-NC-ND 4.0 International license .

characteristics. Participants were instructed to send the swab and the completed questionnaire back to the laboratory via USPS mail immediately after collection. Once delivered, the study coordinator analyzed the fecal swab samples within 48 hours. Detailed microbiologic procedures, including antimicrobial drug susceptibility testing of the $E$. coli isolates, are described in the report by Rubin et al [23].

\subsection{Survey}

The survey questions focused on dietary and behavioral habits that might be associated with the intestinal acquisition of ARG. We asked participants to recall their habits within the 1-year period before completion of the survey questionnaire. The survey instrument was devised partly based on the standard questionnaire used by the Centers for Disease Control and Prevention, Foodborne Disease Outbreak and Surveillance Unit, National Hypothesis Generating Questionnaire (https://www.cdc.gov/foodsafety/outbreaks/surveillance-reporting/investigationtoolkit.html) and was partly based on the instrument used by Manges et al. in a 2007 study investigating the links between retail meat and risk of UTI [27]. Participants were asked to respond according to the following scale: never, past day (24 hours), past week, past month, past year, or more than a year ago. Responses to these questions were dichotomized to reflect modest versus frequent behavior, where the response category that corresponded to a behavior within the past month was defined as frequent. The following information was requested of the participants: biological sex, academic status, meat consumption, dietary restrictions, dairy and egg consumption, raw meat consumption, raw vegetable consumption, preference of organically produced food, number of live-in housemates, location of meal preparation, possession of companion animals, number of sexual partners, history of antibiotic use, history of hospitalization, history of UTI, placement and type of a intrauterine device, and location and duration of travel outside of the United States. 


\subsection{Dataset construction}

To identify the risk factors associated with intestinal carriage of antimicrobial resistance, we compiled a set of 66 variables from our survey that detailed their diet habit, lifestyle, and past antibiotic use. All questions were dichotomized based on frequent ("Yes") or modest ("No") response as described above. We excluded variables for which (1) less than $5 \%$ or more than 95\% of the participants replied "Yes" and (2) more than $10 \%$ of the participants answered "Do not know" or NA. We merged the results from antimicrobial resistance testing to the survey results. Relationships between each set of variables were assessed with correlation coefficients. In this study, we defined isolates with resistance to two or more antimicrobial drug classes as multidrug-resistant and those with resistance to only one drug as drug-resistant.

\subsection{Statistical analysis}

All statistical analyses were conducted with $\mathrm{R}$ version 3.5.1 [28]. First, univariate and multivariate logistic regression analysis was performed. In the multivariate analysis, a model with all potential risk factors were constructed. Then we used R package 'stats' (version 3.5.1) 'step' function with a backward elimination method to determine the best-fitting model. The best- fitting model was determined with Akaike information criteria (AIC) [29]. All tests performed were two-sided, and a P-value $<0.05$ was considered significant.

Penalized regression with the least absolute shrinkage and selection operator (LASSO) models [30] were used to identify variables associated with carriage of multidrug-resistant E. coli.

Association with drug resistance was not tested with LASSO regression due to the high imbalance between the prevalence of drug resistant $E$. coli and drug susceptible E. coli. The LASSO regression functioned as a variable selection process, which reduced the variables to a subset of variables that were consistently related to multidrug resistance. We conducted 10-fold cross validation to select the best fitting model with the minimum mean squared error (MSE). Standard errors were not assessed for LASSO regression model because of its strong bias arising from penalized estimation method. All LASSO regression was performed with R package 'glmnet' (version 2.0.18).

The model performance was evaluated by receiver operating characteristic (ROC) curves and the area under the curve (AUC) was used to classify the participants with and without multidrug- 
medRxiv preprint doi: https://doi.org/10.1101/2020.11.16.20231969; this version posted November 18, 2020. The copyright holder for this preprint (which was not certified by peer review) is the author/funder, who has granted medRxiv a license to display the preprint in perpetuity.

It is made available under a CC-BY-NC-ND 4.0 International license.

resistant E. coli. Hosmer-Lemeshow fit test was used to assess the agreement between observed and model-predicted proportions of carriage of multidrug-resistant E. coli [31]. The difference of AUCs was tested by a nonparametric approach developed by DeLong et al [32].

\section{Results}

\subsection{Background information}

Between June and October 2018, 113 fecal swab samples were collected and cultured, and Gram-negative bacteria were isolated from each culture. Of 113 volunteers, 103 returned both stool sample and the questionnaire. Of 103 stool samples, 93 yielded E. coli colonies on MacConkey plates. Of these, 81 corresponding survey questionnaires had complete response without unanswered questions (Figure 1).

The participants were adults between 18 to 65 years of age (Table 1). Seventy-eight (84\%) of 93 participants whose stool sample was analyzed had E. coli resistant to either ampicillin, trimethoprim-sulfamethoxazole, gentamicin, or colistin, each representing a different class of antimicrobial agent. Of these, $48(52 \%)$ were multidrug resistant, defined as resistance to two or more classes of antimicrobial agents, 30 (32\%) were resistant to only one drug class. Fifteen $(16 \%)$ were susceptible to all the tested drugs.

We compiled the responses to our questionnaire into a dataset with 66 variables and 103 observations (Supplementary Table 1). Variables with (1) more than 10 "Do not know" or (2) $5 \%$ or less "Yes" or "No" were removed from the data to be analyzed. Twenty-six (39\%) of 66 variables were eligible for analysis.

Relationships between each of the predictors under consideration are presented in Figure 2 as correlation coefficients matrix. Females were more likely to report past urinary tract infection (UTI). Those reporting previous antibiotics use had strong correlation with previous UTI. We observed a correlation among employment status and travel status. Also, dietary behaviors were correlated among each factor. There were positive correlations among red meat consumption, poultry consumption, but negative correlations among those reported to have dietary restriction such as being vegan or vegetarian. 


\subsection{Univariate Analysis}

The risk factors associated with the fecal carriage of any drug resistant and multidrug-resistant $E$. coli based on univariate analyses are shown in Table 1. Any drug resistance was compared to those carrying drug-susceptible E. coli, while multidrug-resistance was compared to drugsusceptible and any drug-resistant E. coli. For the carriage of drug resistant E. coli, frequent usage of Supermarket A and previous antibiotic use had a significant association (OR=3.4[95\% confidence interval (CI95\%)1.1-12.4], 4.6 [1.1-31], respectively). All participants who reported to have had past urinary tract infection (UTI) carried drug resistant E. coli. Female gender, undergraduate status, and red meat consumption were significantly associated with carriage of multidrug-resistant E. coli $(\mathrm{OR}=2.8$ [1.1-7.2], 3.9 [1.3-13.2], 2.6 [1.0-6.8], respectively).

\subsection{Multivariate Analysis}

The risk factors associated with the fecal carriage of drug and multidrug-resistant $E$. coli were assessed based on multivariate logistic model (Table 2, Supplementary Table 2). The best fitting multivariate logistic model was determined with a backward elimination method based on AIC.

Fish consumption was negatively associated with the carriage of drug resistant $E$. coli, $(\mathrm{OR}=$ 0.17 [0.03-0.78]) whereas frequent usage of Supermarket A was a risk factor for drug-resistant $E$. coli colonization $(\mathrm{OR}=4.5[1.1-23])$. Female gender $(\mathrm{OR}=2.3[0.76-7.4])$, organic food consumption(OR = 5.7 [0.67-150]), frequent usage of Supermarket B (OR = 3.5 [0.76-22]), and previous antibiotics use $(\mathrm{OR}=4.3[0.89-32])$ included in the model showed positive association with the carriage of drug resistant $E$. coli, but the association was not significant when adjusted for other variables included in the model.

The variables significantly associated with the carriage of multidrug-resistant E. coli include female gender $(\mathrm{OR}=6.1$ [1.9-22]), being undergraduate student $(\mathrm{OR}=5.5$ [1.5-25]), and frequent red meat consumption $(\mathrm{OR}=6.1$ [1.8-24]). Frequent fish consumption was negatively associated with multidrug-resistant $E$. coli carriage $(\mathrm{OR}=0.27$ [0.08-0.85]). Frequent usage of Supermarket B $(\mathrm{OR}=2.6[0.87-8.3])$ and previous travel $(\mathrm{OR}=2.3[0.76-7.4])$ included in the model showed positive association with the carriage of multidrug-resistant E. coli, but the association was not significant when adjusted for other variables included in the model. 


\subsection{Penalized regression with LASSO}

We performed penalized regression with LASSO for parameter selection. Ten-fold crossvalidation was conducted to select optimal estimators. At sigma $=0.05823413$, the mean squared error (MSE) showed the minimum and therefore we selected coefficients at sigma $=$ 0.05823413 as optimum estimators (Figure 3). Estimators are shown in Table 2. Parameters included were female gender $(\mathrm{OR}=1.75)$, undergraduate student $(\mathrm{OR}=1.96)$, frequent red meat consumption $(\mathrm{OR}=1.82)$, frequent fish consumption $(\mathrm{OR}=0.81)$, frequent usage of Supermarket B $(\mathrm{OR}=1.07)$, and previous travel to Europe $(\mathrm{OR}=1.12)$. Of these, all parameters other than previous travel to Europe were consistent with the results obtained from the multivariate model selection based on AIC.

\subsection{Model comparison}

The model performance was evaluated by receiver operating characteristic (ROC) curves (Figure 4). The area under the curves (AUC) of LASSO model and backward elimination method model were 0.79 and 0.82 , respectively $(\mathrm{p}=0.41)$. There was no difference in discrimination accuracy between LASSO model and the model with a backward elimination method.

\section{Discussions}

This study identified potential risk factors associated with fecal carriage of multidrug-resistant $E$. coli among healthy adults at a northern California college community. As far as we know, this is the first study to find association of dietary habits with carriage of multidrug-resistant $E$. coli in healthy United States adult population. Previously, our fecal sample collection and surveillance conducted at the same college community from June to October 2018 identified the prevalence of drug resistant Gram-negative bacteria among healthy volunteers and ARGs carried by these fecal bacteria [23]. We reported the high prevalence of clinically common ARGs and integrons harbored by these Gram-negative bacteria [23]. In the present study, we aimed to identify risk factors for carriage of commensal drug-resistant E. coli.

Overall, the prevalence of drug resistant E. coli was very high in our population, with 78 (84\%) of 93 fecal samples showing resistance to at least one of the antimicrobial drugs tested, which 
included ampicillin, gentamicin, trimethoprim-sulfamethoxazole, and colistin. Of these, 48 (52\%) showed resistance to at least two of these drugs. The prevalence of both drug resistant and multidrug-resistant bacteria was higher than the pooled prevalence (14\%) of a previous study that showed the pooled prevalence of drug resistant E. coli in the world [24] and even higher than the study with highest prevalence $(51 \%)$ that targeted population after international travel conducted in Germany [33]. Unadjusted ORs revealed that while carriage of drug resistant $E$. coli was positively associated with frequent usage of supermarket $\mathrm{A}$ and previous antibiotics use, carriage of multidrug-resistant $E$. coli was positively associated with female gender and frequent red meat consumption. Other than the frequent usage of supermarket $\mathrm{A}$, these findings are consistent with a previous report showing antibiotics use and female gender to be associated with the fecal carriage of drug resistant bacteria [24] and multiple reports showing the isolation of multidrug-resistant $E$. coli from retail meat [27,34,35].

We used multiple methods to identify risks. Since our sample size was small and was subject to overfitting under multivariate logistic regression model, we used a penalized regression method LASSO as well to select features by shrinking less important coefficients to zero and to avoid overfitting [30]. Still, features selected by LASSO are highly biased and unstable. Therefore, we implemented two methods to confirm the consistency of the outcome of model selection. Model selection for estimating the risk of multidrug-resistant $E$. coli carriage showed consistent result with univariate analysis in both multivariate logistic regression backward elimination method and LASSO regression method. Backward elimination method with AIC and LASSO method both identified female gender, being an undergraduate student, frequent red meat consumption, and frequent usage of supermarket B as positively associated and frequent fish consumption as negatively associated with the carriage of multidrug-resistant E. coli. Factors related to previous travel was included in both models but were not significant nor consistent. Red meat consumption had an almost 6-fold increase and fish consumption had an almost 4-fold decrease in risk of the carriage of multidrug-resistant $E$. coli, when adjusted by gender, employment status, frequently used supermarket, and travel status. Similar trend is observed for LASSO model, showing $80 \%$ increase and $20 \%$ decrease for red meat and fish consumption respectively, adjusted by gender, employment status, frequently used supermarket, and travel status. 
Red meat has been recognized to contain $E$. coli strains harboring drug resistant genes and therefore it was not surprising that frequent consumption of red meat was strongly associated with the carriage of multidrug-resistant bacteria [11,35]. Fish, however, has also been reported to be colonized with multidrug-resistant bacteria and multiple drug resistance genes [36,37], and yet we observed a negative association with both drug resistant and multidrug-resistant E. coli carriage in multivariate logistic regression models. From this study we cannot draw any causal relationship between frequent fish consumption and low carriage of drug resistant bacteria because of the potential unmeasured confounders related to frequent fish consumption and to the carriage of drug resistant bacteria.

Model performance of multivariate logistic regression and LASSO regression was compared with ROC. For our study these two models' performance was equally moderate. One of the limitations of our study is the small sample size and the high imbalance between the prevalence of carriage of single-drug resistant bacteria and that of drug susceptible bacteria. Although this strong imbalance itself suggests the serious public health impact of antimicrobial resistance in the study college community, we could not assess risk factor for the carriage of any drug resistant bacteria with the LASSO method. Still, we were able to determine risk factors associated with the carriage of multidrug-resistant bacteria based on the two regression methods. The second limitation of our study is that we contacted and recruited the study participants from a restricted community - a college community. The risk factors we found may not be generalizable to other populations elsewhere. Additional studies are needed to confirm that the risk factors we found occur in other regions of the United States or other countries. However, the strength of limiting the study population to a college community is that we can control for potential unmeasured confounders such as access to food, access to health care, and other socioeconomic status.

Our third limitation is that we relied on self-reports by the participants for an assessment of their dietary behavior. Our outcome of interest, the carriage of drug resistant bacteria, was systematically tested in the laboratory. Still, our study was a cross sectional study that simultaneously accessed the outcome and the exposures related to food. Therefore, we can assume overreporting or underreporting was non-differential and any measures of association would bias toward the null, if any. 
It is made available under a CC-BY-NC-ND 4.0 International license .

\section{Conclusion}

Among healthy adults in a college community in Northern California, female gender, being an undergraduate student, and frequent consumption of red meat was significantly associated with increased risk of being colonized with multidrug-resistant $E$. coli, while frequent consumption of fish was negatively associated. Further studies with a larger population and at other locations will be essential for establishing the generalizability of our finding and to devise public health interventions that can decrease the colonization by drug resistant bacteria.

\section{Acknowledgement}

We would like to thank Dr. Reina Yamaji for her assistance in the study design process, as well as Dr. Clarissa Araujo Borges for her consistent support in classification of the study isolates. We would also like to thank the University instructors who were instrumental in recruitment for this study. We would also like to the University Department of Environmental Health and Safety for their assistance in ensuring safe shipment of biological specimens.

\section{Authors' contributions}

YH performed the statistical analysis; participated in data interpretation; prepared tables and figures; wrote and drafted the manuscript; and agreed to be accountable for all aspects of the work by ensuring that questions related to the accuracy or integrity of any part of the work were appropriately investigated and resolved. JR conceptualized and designed the survey; participated in data collection; conducted laboratory testing; drafted the manuscript. KM conducted laboratory testing; participated in data collection and extraction. LWR conceptualized and designed the survey; reviewed and revised the manuscript; and agreed to be accountable for all aspects of the work by ensuring that questions related to the accuracy or integrity of any part of the work were appropriately investigated and resolved.

All authors read and approved the final manuscript. 


\section{References}

1. World Health Organization (WHO). Global Antimicrobial Resistance and Use Surveillance System (GLASS) Report. 2020; .

2. World Health Organization (WHO). Global Action Plan on Antimicrobial Resistance. 2015; .

3. U.S. Department of Health \& Human Services. NATIONAL ACTION PLAN FOR COMBATING ANTIBIOTIC-RESISTANT BACTERIA 2020-2025. 2020; . Available from: https://aspe.hhs.gov/system/files/pdf/264126/CARB-National-Action-Plan-20202025.pdf

4. Centers for Disease Control and Prevention. Antibiotic resistance threats in the United States. 2019; . Available from: https://www.cdc.gov/drugresistance/biggest_threats.html

5. WHO (World Health Organisation). ANTIMICROBIAL RESISTANCE Global Report on Surveillance. 2014; . Available from: http://apps.who.int/iris/bitstream/10665/112642/1/9789241564748_eng.pdf?ua=1

6. Johnson JR, Russo TA. Extraintestinal pathogenic Escherichia coli: "The other bad E coli.” J Lab Clin Med. 2002; 139(3):155-162.

7. Thaden JT, Jr VGF, Sexton DJ, Anderson DJ. Increasing Incidence of Extended-Spectrum $\beta$-Lactamase- Producing Escherichia coli in Community Hospitals throughout the Southeastern United States. Infect Control Hosp Epidemiol. 2016; 37(1):49-54.

8. Allocati N, Masulli M, Alexeyev MF, Ilio C Di. Escherichia coli in Europe: An overview. Int J Environ Res Public Health. 2013; 10(12):6235-6254.

9. Kaushik M, Kumar S, Kapoor RK, Gulati P. Integrons and antibiotic resistance genes in water-borne pathogens: Threat detection and risk assessment. J Med Microbiol. 2019; 68(5):679-692.

10. Saliu EM, Vahjen W, Zentek J. Types and prevalence of extended-spectrum betalactamase producing Enterobacteriaceae in poultry. Anim Heal Res Rev. 2017; 18(1):4657.

11. Yamaji R, Friedman CR, Rubin J, et al. A Population-Based Surveillance Study of Shared Genotypes of Escherichia coli Isolates from Retail Meat and Suspected Cases of Urinary Tract Infections . mSphere. 2018; 3(4):1-12.

12. Raphael E, Wong LK, Riley LW. Extended-Spectrum Beta-Lactamase Gene Sequences in Gram-Negative Saprophytes on Retail Organic and Nonorganic Spinach. Appl Environ Microbiol [Internet]. American Society for Microbiology Journals; 2011; 77(5):16011607. Available from: https://aem.asm.org/content/77/5/1601

13. Sapkota S, Adhikari S, Pandey A, et al. Multi-drug resistant extended-spectrum betalactamase producing E. coli and Salmonella on raw vegetable salads served at hotels and restaurants in Bharatpur, Nepal. BMC Res Notes [Internet]. 2019; 12(1):516. Available from: https://doi.org/10.1186/s13104-019-4557-9 
14. Weiner LM, Webb AK, Limbago B, et al. Antimicrobial-Resistant Pathogens Associated with Healthcare-Associated Infections: Summary of Data Reported to the National Healthcare Safety Network at the Centers for Disease Control and Prevention, 2011-2014. Infect Control Hosp Epidemiol. 2016; 37(11):1288-1301.

15. Donskey CJ. The Role of the Intestinal Tract as a Reservoir and Source for Transmission of Nosocomial Pathogens. Clin Infect Dis [Internet]. 2004; 39(2):219-226. Available from: https://doi.org/10.1086/422002

16. Carlet J. The gut is the epicentre of antibiotic resistance. Antimicrob Resist Infect Control. 2012; 1(1):1.

17. Barlow M. What Antimicrobial Resistance Has Taught Us About Horizontal Gene Transfer. In: Gogarten MB, Gogarten JP, Olendzenski LC, editors. Horiz Gene Transf Genomes Flux [Internet]. Totowa, NJ: Humana Press; 2009. p. 397-411. Available from: https://doi.org/10.1007/978-1-60327-853-9_23

18. Centers for Disease Control and Prevention. E. coli (Escherichia coli) Prevention [Internet]. 2017. Available from: https://www.cdc.gov/ecoli/ecoli-prevention.html

19. Costelloe C, Metcalfe C, Lovering A, Mant D, Hay AD. Effect of antibiotic prescribing in primary care on antimicrobial resistance in individual patients: Systematic review and meta-analysis. BMJ. 2010; 340(7756): 1120.

20. Karanika S, Karantanos T, Arvanitis M, Grigoras C, Mylonakis E. Fecal Colonization with Extended-spectrum Beta-lactamase-Producing Enterobacteriaceae and Risk Factors among Healthy Individuals: A Systematic Review and Metaanalysis. Clin Infect Dis. 2016; 63(3):310-318.

21. Cornejo-Juárez P, Vilar-Compte D, Pérez-Jiménez C, Namendys-Silva SA, SandovalHernández S, Volkow-Fernández P. The impact of hospital-acquired infections with multidrug-resistant bacteria in an oncology intensive care unit. Int J Infect Dis. 2015; 31:e31-e34.

22. Sabir N, Ikram A, Zaman G, et al. Bacterial biofilm-based catheter-associated urinary tract infections: Causative pathogens and antibiotic resistance. Am. J. Infect. Control. 2017. p. 1101-1105.

23. Rubin J, Mussio K, Xu Y, Suh J, Riley LW. Prevalence of antimicrobial resistance genes and integrons in commensal Gram-negative bacteria in a college community. Microb Drug Resist. 2020; 26(10):1227-1235.

24. $\mathrm{Hu}$ Y, Matsui Y, Riley LW. Risk factors for fecal carriage of drug-resistant Escherichia coli $\square$ : a systematic review and meta-analysis. Antimicrob Resist Infect Control. Antimicrobial Resistance and Infection Control; 2020; 3:1-12.

25. Caudell MA, Mair C, Subbiah M, et al. Identification of risk factors associated with carriage of resistant Escherichia coli in three culturally diverse ethnic groups in Tanzania: a biological and socioeconomic analysis. Lancet Planet Heal. Netherlands; 2018; 2(11):e489-e497. 
26. Arcilla MS, Hattem JM van, Haverkate MR, et al. Import and spread of extendedspectrum beta-lactamase-producing Enterobacteriaceae by international travellers (COMBAT study): a prospective, multicentre cohort study. LANCET Infect Dis. 2017; 17(1):78-85.

27. Manges AR, Smith SP, Lau BJ, et al. Retail meat consumption and the acquisition of antimicrobial resistant Escherichia coli causing urinary tract infections: a case-control study. Foodborne Pathog Dis [Internet]. 2007; 4(4):419-431. Available from: http://www.ncbi.nlm.nih.gov/entrez/query.fcgi?cmd=Retrieve \&db=PubMed\&dopt=Citati on\&list_uids $=18041952$

28. R Core Team. R: A Language and Environment for Statistical Computing [Internet]. Vienna, Austria; 2018. Available from: https://www.r-project.org/

29. Wagenmakers EJ, Farrell S. AIC model selection using Akaike weights. Psychon Bull Rev. 2004; 11(1):192-196.

30. Tibshirani R. Regression shrinkage and selection via the Lasso [Internet]. J. R. Stat. Soc. Ser. B. 1996. p. 267-288. Available from: https://statweb.stanford.edu/ tibs/lasso/lasso.pdf

31. Hosmer DW, Lameshow S. Applied Logistic Regression. New York Wiley. 1989; .

32. DeLong ER, DeLong DM, Clarke-Pearson DL. Comparing the areas under two or more correlated receiver operating characteristic curves: A nonparametric approach. Biometrics. 1988; 44:837-845.

33. Miranda IB, Ignatius R, Pfueller R, et al. High carriage rate of ESBL-producing Enterobacteriaceae at presentation and follow-up among travellers with gastrointestinal complaints returning from India and Southeast Asia. J Travel Med. 2016; 23(2).

34. Yamaji R, Friedman CR, Rubin J, et al. A Population-Based Surveillance Study of Shared Genotypes of Escherichia coli Isolates from Retail Meat and Suspected Cases of Urinary Tract Infections. mSphere [Internet]. 2018; 3(4):e00179-18. Available from: http://www.ncbi.nlm.nih.gov/pubmed/30111626

35. Tyson GH, Li C, Hsu CH, Bodeis-Jones S, McDermott PF. Diverse Fluoroquinolone Resistance Plasmids From Retail Meat E. coli in the United States. Front Microbiol. 2019; 10(December):1-7.

36. Ryu SH, Park SG, Choi SM, et al. Antimicrobial resistance and resistance genes in Escherichia coli strains isolated from commercial fish and seafood. Int J Food Microbiol [Internet]. Elsevier B.V.; 2012; 152(1-2):14-18. Available from: http://dx.doi.org/10.1016/j.ijfoodmicro.2011.10.003

37. Buschmann AH, Tomova A, López A, et al. Salmon aquaculture and antimicrobial resistance in the marine environment. PLoS One. 2012; 7(8):26-28. 


\section{Figures and Tables}

Figure 1: Flowchart of study samples

Figure 2: Correlation matrix for potential risk factors

Figure 3: Plots for LASSO regression coefficients and cross validation over different values of the penalty parameter MSE: mean squared error

Figure 4: ROC curve Discrimination performance of LASSO model for fecal carriage of multidrug-resistant $E$. coli and comparison with backward elimination method model by receiver-operator characteristic analyses. Red: GLM backward elimination method model, green: LASSO model.

Table 1: Univariate analysis of potential risk factors for fecal carriage of MDR E. coli

Table 2: Result of multivariate logistic regression with backward elimination model and LASSO model

Supplementary Table 1: Result from survey without removing NAs 
Table 1

\begin{tabular}{|c|c|c|c|}
\hline & $\begin{array}{l}\text { No. of population } \\
(\%)\end{array}$ & $\begin{array}{l}\text { No. of samples with } \\
\text { MDR E. coli }(\%)\end{array}$ & OR [CI95\%] \\
\hline Gender (Female) & $49(61)$ & $29(59)$ & $2.77[1.12-7.17]$ \\
\hline \multicolumn{4}{|l|}{ Employment } \\
\hline Undergrad student & $19(24)$ & $14(74)$ & $3.88[1.31-13.24]$ \\
\hline Graduate student & $37(46)$ & $15(41)$ & $0.52[0.21-1.25]$ \\
\hline Staff & $23(28)$ & $10(44)$ & 0.72 [0.27-1.89] \\
\hline \multicolumn{4}{|l|}{ Dietary habit } \\
\hline Poultry & $64(79)$ & $34(53)$ & $2.08[0.70-6.67]$ \\
\hline Red meat & $52(64)$ & $30(58)$ & 2.59 [1.03-6.85] \\
\hline Fish & $31(38)$ & $12(39)$ & $0.50[0.20-1.23]$ \\
\hline Raw meat/fish & $43(53)$ & $22(51)$ & $1.16[0.49-2.81]$ \\
\hline Raw vegetable & $79(98)$ & $39(49)$ & $0.98[0.04-25.24]$ \\
\hline Diet restriction & $19(24)$ & $8(42)$ & $0.68[0.24-1.91]$ \\
\hline Organic food & $17(21)$ & $9(53)$ & $1.20[0.41-3.57]$ \\
\hline Living with roommate & $71(88)$ & $36(51)$ & $1.54[0.41-6.48]$ \\
\hline Food made at home & $72(89)$ & $35(49)$ & $0.76[0.18-3.08]$ \\
\hline Food from outside home & $30(37)$ & $16(53)$ & $1.29[0.52-3.20]$ \\
\hline \multicolumn{4}{|l|}{ Supermarket } \\
\hline A & $49(61)$ & $25(51)$ & $1.18[0.48-2.90]$ \\
\hline $\mathrm{B}$ & $37(46)$ & $21(57)$ & $1.73[0.72-4.23]$ \\
\hline $\mathrm{C}$ & $31(38)$ & $13(42)$ & $0.62[0.25-1.51]$ \\
\hline other grocery shop & $31(38)$ & $13(42)$ & $0.62[0.25-1.51]$ \\
\hline Pet & $22(27)$ & $10(46)$ & $0.81[0.30-2.15]$ \\
\hline \multicolumn{4}{|l|}{ Travel } \\
\hline travel within one year & $51(63)$ & $28(55)$ & $1.83[0.74-4.65]$ \\
\hline $\begin{array}{l}\text { travel longer than } 1 \\
\text { month }\end{array}$ & $27(33)$ & $15(56)$ & $1.45[0.57-3.72]$ \\
\hline Southeast Asia & $4(5)$ & $2(50)$ & $1.03[0.12-8.91]$ \\
\hline East Asia & $10(12)$ & $5(50)$ & $1.03[0.27-4.00]$ \\
\hline
\end{tabular}


medRxiv preprint doi: https://doi.org/10.1101/2020.11.16.20231969; this version posted November 18, 2020. The copyright holder for this preprint (which was not certified by peer review) is the author/funder, who has granted medRxiv a license to display the preprint in perpetuity.

It is made available under a CC-BY-NC-ND 4.0 International license .

Central and South

America

$21(26)$

$10(48)$

$0.91[0.33-2.47]$

Europe

$27(33)$

$16(59)$

$1.82[0.72-4.73]$

\section{Medical history}

previous antibiotics use

$31(38)$

$18(58)$

$1.76[0.72-4.43]$

past UTI

12 (15)

$6(50)$

$1.03[0.30-3.60]$

\section{Others}

Living with roommate

$71(88)$

$36(51)$

1.54 [0.41-6.48] 
medRxiv preprint doi: https://doi.org/10.1101/2020.11.16.20231969; this version posted November 18, 2020. The copyright holder for this preprint (which was not certified by peer review) is the author/funder, who has granted medRxiv a license to display the preprint in perpetuity.

It is made available under a CC-BY-NC-ND 4.0 International license .

\section{Table 2}

\begin{tabular}{lcrrr} 
& Multivariate logistic regression & \multicolumn{2}{c}{$\begin{array}{c}\text { LASSO } \\
\text { regression }\end{array}$} \\
& OR & $95 \%$ CI & P-value & OR \\
\hline Female gender & 6.06 & $1.92-22.5$ & 0.004 & 1.75 \\
Undergraduate & 5.46 & $1.47-25.1$ & 0.017 & 1.96 \\
Red meat & 6.13 & $1.83-24.2$ & 0.005 & 1.82 \\
Fish & 0.27 & $0.08-0.85$ & 0.032 & 0.81 \\
Supermarket B & 2.56 & $0.87-8.28$ & 0.098 & 1.07 \\
Travel within 1 year & 2.29 & $0.87-8.28$ & 0.14 & - \\
Travel to Europe & - & - & - & 1.12 \\
\hline AUC & 0.82 & & & 0.79
\end{tabular}


Volunteers from a college community (Jun-Oct, 2018)

medRxiv preprint doi: https://doi org/10 101/2020.11.16.20231969; this version posted November 18, $2020=113$ The copyright holder for this

It is made available under a CC-BY-NC-ND 4.0 International license.

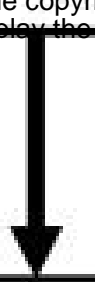

Volunteers from a college community with survey response $n=103$

Stool sample eligible for laboratory testing $\mathrm{n}=93$

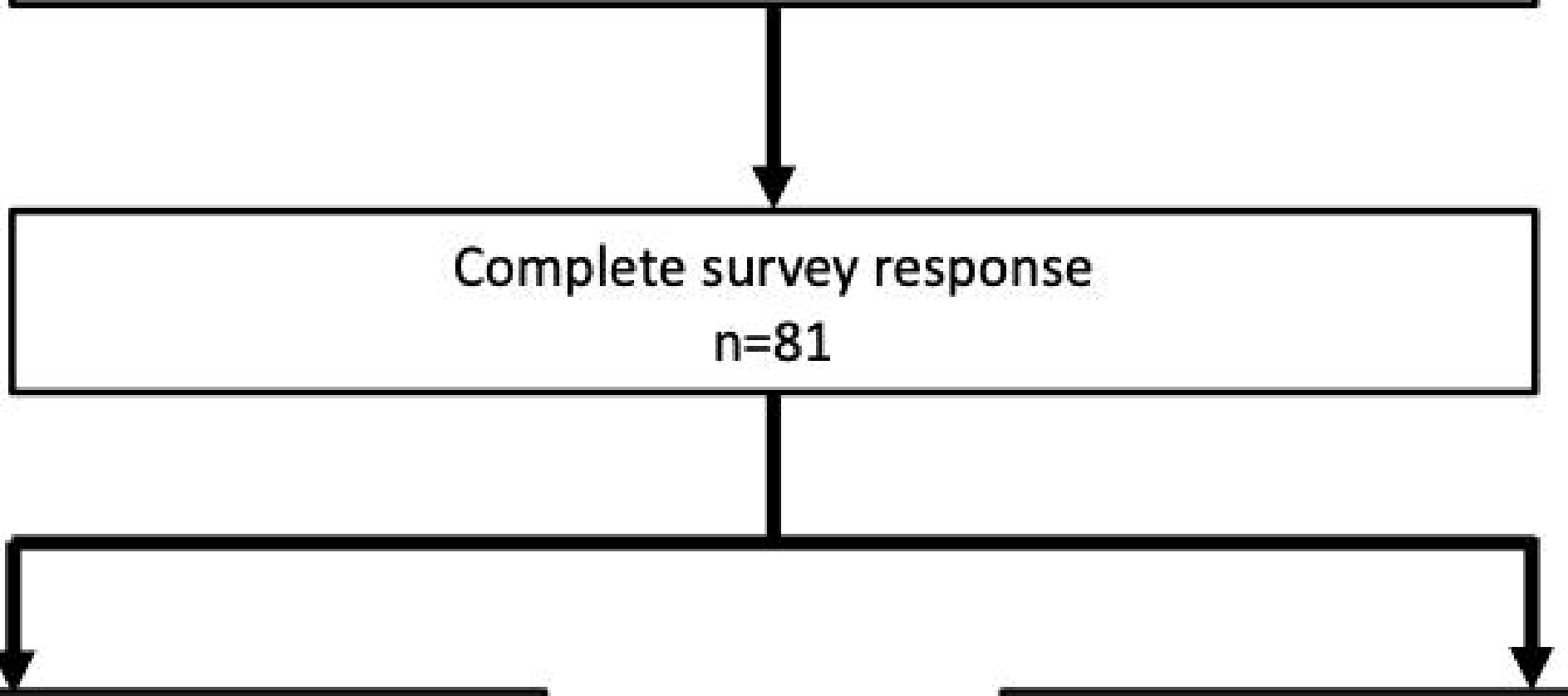

Eligible, participants with MDR E.coli

Eligible, participants without MDR E. coli $\mathrm{n}=40$ $n=41$ 
othergroceryshop supermarketC supermarketB supermarketA
outhomefood outhomefood -
home roommate organic dietrestriction rawvege rawmonth redmeat poultry employment_Staff employment_grad employment_undergrad gender

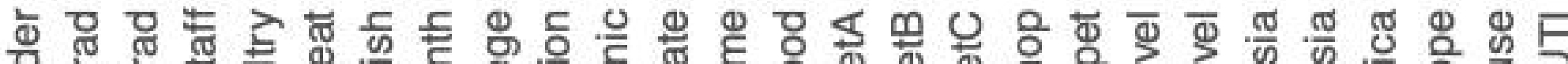

$$
\begin{aligned}
& \text { 는 ๘ } \\
& \text { 㟧 } \\
& \text { 믈 등 ญ } \\
& \text { ป ह } \\
& + \text { ำ ำ } \\
& \text { 도응 응 } \\
& \text { ह ह ह } \\
& \text { 응 } \\
& \text { 틈 }
\end{aligned}
$$

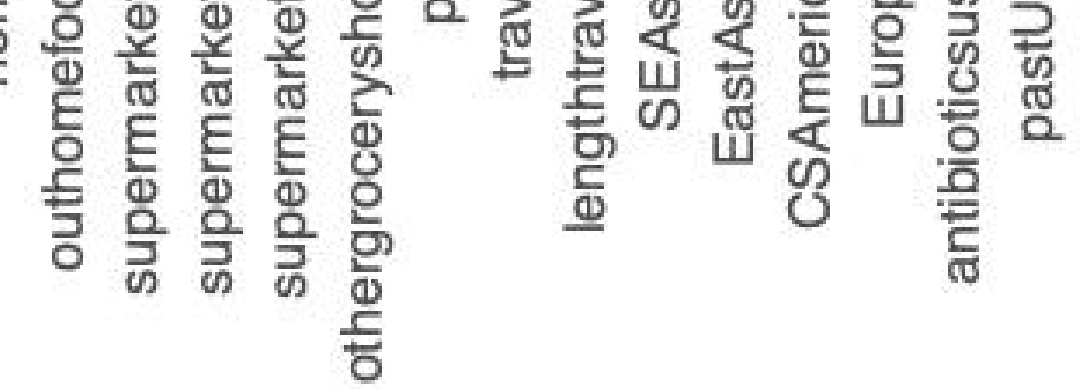

Correlation

1.0

0.5

0.0

$-0.5$ 
